of the earth can be made fertile. There are places incapable of being afforested, which would not give the necessary nourishment to trees.

\section{ORIGIN OF THE CEREALS}

$\mathrm{R}$ ECENT numbers of Naturen contain interesting papers, by $\mathrm{R}$ Prof. Schibeler, on the original habitat of some of the cereals, and the subsequent cultivation in the Scandinavian lands and Iceland of barley and rye more especially. It would appear that barley was cultivated before other cereals in Scandinavia, and that the generic term "corn" was applied among Northmen to this grain only from the oldest times, and that in the Nor. wegian laws of the seventeenth and eighteenth centuries wherever reference was made to the "Kornskat" - or standard by which land in the Northern lands was, and still is, rated in accordance with the corn it is capable of yielding-the term was understood to apply to barley. Proof of the high latitude to which the cultivation was carried in early ages is afforded by the Egil's Saga, where mention is made of a barn in Helgeland $\left(65^{\circ} \mathrm{N}\right.$. lat.) used for the storing of corn, and which was so large that tables could be spread within it for the entertainment of 800 guests. In Iceland barley was cultivated from the time of its colonisation, in 870 , till the middle of the fourteenth century, or, according to Jón Storrason, as lately as 1400. From that period down to our own times barley has not been grown in Iceland with any systematic attention, the islanders being dependent on the home country for their supplies of corn. In the last century, however, various attempts were made both by the Danish Government and private individuals to obtain homegrown corn in Iceland, and the success with which these endeavours were attended gives additional importance to the systematic undertaking, which has been set on foot by Dr. Schuibeler and others, within the last three years, for the introduction into the island of the hardier cereals, vegetables, and fruits. As many as 382 samples of seeds of ornamental and useful plants, most of which were collected from the neighbourhood of Christiania, are now being cultivated at Reykjavik under the special direction of the local government doctor, Herr Schierbeck, who succeeded in 1883 in cutting barley ninety-eight days after the sowing of the seed, which had come from Alten $\left(70^{\circ} \mathrm{N}\right.$. lat.). And here it may be observed that this seems the polar limit in Norway for anything like good barley crops. The seed is generally sown at the end of May, and in favourable seasons it may be cut at the end of August; the growth of the stalk being often $2 \frac{1}{2}$ inches in twenty-four hours. North of $60^{\circ}$ or $6 \mathbf{I}^{\circ}$ barley cannot be successfully grown in Norway at more than from I800 to 2000 feet above the sea-level. In Sweden the polar limit is about $68^{\circ}$ or $66^{\circ}$, but even there, as in Finland, night-frosts prove very destructive to the young barley. In some of the fjeld valleys of Norway, on the other hand, barley may in favourable seasons be cut eight or nine weeks after its sowing, and thus two crops may be reaped in one summer. According even to a tradition current in Thelemarken, a farm there owes its name Triset to the three crops reaped in the land in one year! Rye early came into use as a hread-stuff in Scandinavia, and in 1490 the Norwegian Council of State issued an ordinance making it obligatory on every peasant to lay down a certain proportion of his land in rye. In Norway the polar limit of summer rye is about $69^{\circ}$, and that of winter rye about $61^{\circ}$; but in Sweden it has been carried along the coast as far north as $55^{\circ}$. The summer rye crops are generally sown and fit for cutting about the same time as barley, although occasionally in Southern Norway less than ninety days are required for their full maturity.

\section{UNIVERSITY AND EDUCATIONAL INTELLIGENCE}

The Gilchrist Trustees have instituted a Scholarship of the annual value of $50 \%$, for three years, tenable at either Girton or Newnham College, Cambridge, to be awarded in connection with the Cambridge Higher Local Examination. 'The first award will be made on the results of the examination to be held in June. Further information may be obtained from the secretaries of the two colleges.

AT a recent meeting of the Senate of the Royal University of Ireland, two Fellows in the Department of Natural Science were elected. The successful competitors were the Rev. Marshal
L. Klein, of the Catholic University College, and Mr. Marcus M. Hartog, Professor of Natural History, Queen's College, Cork. The salary attached to each of the Fellowships is $400 l$. a year.

\section{SCIENTIFIC SERIALS}

The Qurterly Fournal of Microscopical Science, April, contains :-On the urinary organs of the Amphipoda, by W. B. Spencer, B.A. (plate 13). - The skin and nervous system of Priapulus and Halicryptus, by R. Scharff, Ph.D. (plate 14).The eye and optic tract of insects, by S. J. Hickson, B.A. (plates I 5-1 7). - A peculiar sense organ in Scutigera coleoptrata, one of the Myriopoda, by F. G. Heathcote, B.A. (plate 18). The structure and development of Loxosoma, by S. F. Harmer B. Sc. (plates I9-2I). - A new hypothesis as to the relationship of the lung-book of Scorpio to the gill-book of Limulus, by $\mathrm{E}$. R. Lankester, M.A.-A supplement number is announced to be published during May.

The Fournal of the Royal Microscopieal Society for April contains :-The Rev. W. H. Dallinger's address as President (plates 4-6). - The Lantern Microscope, by L. Wright. - On some unusual forms of lactic ferment; Bacterium lactis, by R. L. Maddox, M. D.-On a cata-dioptric immersion illuminator, by J. W. Stephenson. - With the usual summary of current researches in zoology and botany.

American Fournal of Science, May.-Experiments undertaken to determine the modulus of elasticity of ice and the velocity of sound in ice, by John Trowbridge and Austin L. McRae. The average of all the observations was found to be $72 \times 10^{9}$ as compared with Bevan's absolute modulus $54 \times 10^{9}$. The velocity was determined at $2900 \mathrm{~m}$. per second, or about nine times the velocity of sound in air.-Contributions from the Agricultural Experiment Station of the University of Wisconsin : digestion experiments, by H. P. Armsby. These experiments, made on sheep fed with hay, clover, malt-sprouts, and cotton seed-meal, yielded so many uncertain results that no satisfactory averages could be determined. Such averages may be made the basis of the calculation of rations in practice; but neither they nor the single results upon any given fodder can properly enter into any scientific calculation of the nutritive effect of a ration.-Chemical analysis of massive safflorite, by Le Roy W. McCay.-Application of photography to the study of electrical measurements (two illustrations), by John Trowbridge and Hammond Vinton Hayes. On the production of alternating currents by means of a directcurrent dynamo-electric machine, by John Trowbridge and Hammond Vinton Hayes. - Chemical analysis of a variety of topaz discovered in $\mathbf{I} 882$ by Mr. N. H. Perry in the Stoneham district, State of Maine (two illustrations), by F. W. Clarke and J. S. Diller. - A notice of the relation observed by Dr. Weber between the residual elasticity and the chemical constitution of glass, by O. T. Sherman.-On the meridional deflection of ice-streams, as shown in the morains s of the extinct glaciers in the Mono Lake Valley, Eastern California (two illustrations), by W. J. McGee.-The pre-Glacial channel of Eagle River, Keweenaw Point, Lake Superior (one illustration), by Charles Whittlesey.-Note on the age of the slaty and arenaceous rocks in the vicinity of Schenectady, Schenectady County, New York, by S. W. Ford. These formations, usually referred to the epoch of the Lorraine shales, are regarded by the author as belonging to the Utica age. From them were obtained various fossils, including a species of Lingula which he considers to be the Utica species, L. curta.

The American Naturalist, March, contains :-Indian corn and the Indians, by E. L. Sturtevant.-The evolution of the Vertebrata, progressive and retrogressive, by E. D. Cope.-On the larval forms of Spirorbis borealis, by J. W. Fewkes. - Pennsylvania, before and after the elevation of the Appalachian Mountains ; a study in dynamical geology, by E. W. Claypole.-Life and nature in Southern Labrador, by A. S. Packard.

April. - Why certain kinds of timber prevail in certain localities, by J. T. Campbell.-The evolution of the Vertebrata, by E. D. Cope--Progress of North American Invertebrate palæontology for 1884 , by J. B. Marcou. - The clam-worm, by S. Lockwood. - Life and nature in Southern Labrador, by A. S. Packard.

May.-Some new Infusoria (with illustrations), by A. C. Stokes. - Kitchen-garden esculents of American origin (I.), by E. L. Sturtevant.-The Lemuroifea and the Insectivora of the 
Eocene period of North America (illustrated), by E. D. Cope. -On the Labrador Eskimo and their former range southward, by A. S. Packard.

Rendiconti del Reale Istituto Lombardo, April 23.--Some formulas for the calculation of the momenta of inertia in plain polygons, by Prof. G. Bardelli.-Some remarks on the functions which satisfy the differential equation $\Delta^{2} u=0$, by Prof. Giulio Ascoli. - Note on the norphological distinction between the various homologous and analogous organs of the different orders in the animal kingdom, by E. L. Maggi.-On a generalisation of the involute properties of complete squares and quadrilateral figures, by Gino Loria.- - On a method of plain representation for the descriptive geometry of ordinary space, by Prof. F. Aschieri. - On the discontinuities in the secondary derived forms of the potential functions of a surface, by Dr. Paolo Paci.-Meteorological observations made in the Royal Brera Observatory, Milan, during the month of April.

Rivista Scientifico-Industriale, April 15-30.-Remarks on the velocity of the wind in connection with Prof. Archibald's experiments with Biram's anemometers, by the Editor.-Variations in the electric resistance of solid and pure metallic wires, according to the temperature (continued), by Prof. Angelo Emo.Description of a new steam generator based on the principle of vortex circulation, by Prof. Annibale Ricco.-Note on the Emberiza intermedia discovered by Dr. Michaellis in Dalmatia; is it a distinct species in this family of birds ? by Dante Roster

\section{SOCIETIES AND ACADEMIES LONDON}

Royal Society, May 7.- "Contributions to the Chemistry of Chlorophyll. Part I.," by Edward Schunck, F.R.S.

The paper treats of the products formed by the action of acids on chlorophyll. All who have worked with chlorophyll are familiar with the peculiar effects produced in solutions of chlorophyll by the action of acids. The colour is changed, and an absorption spectrum makes its appearance, which differs from that of chlorophyll. According to some, these changes are due to a simple modification of the chlorophyll, others consider they are caused by the formation of products of decomposition. The latter view seems the more probable.

On passing a current of hydrochloric acid gas into an alcoholic solution of chlorophyll, a dark green, almost black, precipitate is formed at once. The greenish-yellow liquid contains substances extracted along with chlorophyll by the alcohol, and not connected with the latter. The precipitate consists essentially of two colouring matters, phyllocyanin and phylloxanthin, bodies that had been previously observed and so named by Fremy, who, however, did not obtain them in a state of purity. They are best separated by Fremy's method, which consists in dissolving the mixture in ether, and then adding concentrated hydrochloric acid, when the liquid separates into two layers, a lower blue one containing phyllocyanin and an upper yellowish green one containing phylloxanthin. It is immaterial what kind of leaves are taken for extraction, the products are always the same.

The paper deals only with the properties of phyllocyanin, which are very peculiar. After being purified in the manner described, it is obtained as a dark blue mass resembling indigo, and consisting of microscopic crystals which are generally opaque, but sometimes when very thin are translucent, and then appear olive-coloured. It stands heating to $160^{\circ}$ without decomposition, but between that temperature and $180^{\circ}$ it is decomposed without previously fusing, leaving a charred mass whicb, on further heating, burns away without residue. It contains nitrogen, but is free from sulphur.

Phyllocyanin is insoluble in water, petroleum ether, and ligroin, but dissolves in alcohol, ether, chloroform, glacial acetic acid, benzol, aniline, and carbon disulphide. The best solvent is chloroform. A mirute quantity of the substance imparts an intense colour to any one of these solvents. It is only on diluting largely that the solutions lose their opacity. They then appear of a dull green or olive colour, and show the well-known and often described spectrum of so-called "acid chlorophyll," consisting of five bands, three of which are very dark, one of moderate intensity, and the fifth very faint.

By oxidising agents, such as nitric or chromic acid, phyllocyanin is easily decomposed, yielding yellow amorphous prorlucts, the solutions of which show no absorption bands. It shows a remarkable degree of permanence as compared with chlorophyll, when exposed to the combined action of air and light. A chloroformic solution contained in a loosely-stoppered bottle may be exposed for weeks, or even months, to alternate sunlight and diffused daylight before its peculiar colour and all trace of absorption bands have disappeared. When the process is complete a yellow liquid results, which contains several products, all of them amorphous, one being easily soluble in water, and exceedingly bitter to the taste. The decoloration of a chlorophyll solution under the same circumstances would take place in a day or two.

Phyllocyanin dissolves easily in concentrated sulphuric, hydrochloric, and hydrobromic acids, yielding dark blue solutions, which show spectra differing from that of phyllocyanin, and no doubt contain compounds of the latter with acids. These compounds, however, are unstable ; for, on the addition of water to the solutions, phyllocyanin is precipitated unchanged. Phyllocyanin shows no tendency to combine with weaker acids, such as phosphoric, oxalic, tartaric, or citric acid.

Phyllocyanin dissolves easily in dilute caustic potash or soda lye. The solution gives precipitates of various shades of green with earthy and metallic salts, such as barium chloride, calcium chloride, lead acetate, and cupric acetate, and these might be called phyllocyanates. It seems, however, that by mere solution in alkali, phyllocyanin undergoes some change, for if acetic acid in excess be added to the solution, and it be then shaken up with ether, the precipitate dissolves in the ether, giving a solu tion which shows the bands of phyllocyanin; but if the whole be left to stand some time, the colour of the ethereal solution changes from green to brown, and it now shows a distinct and peculiar spectrum, characterised by two bands in the red and two fine but well-marked bands in the green, the third and fourth bands of phyllocyanin having disappeared, while the fifth still remains. The body yielding this spectrum has been prepared and found to yield microscopic crystals like phyllocyanin. A different product is formed when hot alkaline lye, or, what is better, boiling alcoholic potash or soda, is employed. It crystallises in small rosettes, which are green by transmitted, of a fine purple by reflected, light. Its solutions have a dull purple colour, and exhibit a distinct spectrum characterised by a broad, very dark band in the green. It may be identical with one of the products obtained by Hoppe-Seyler from his chlorophyllan with alkalis.

The concluding part of the paper treats of what may be called double compounds of phyllocyanin, into which metals and acids, especially organic acids, enter as constituents. Phyllocyanin seems to act the part of a weak base, uniting with strong acids and forming unstable compounds. In acetic acid it merely dissolves without yielding any compound. In like manner, when freshly precipitated cupric oxide or zinc oxide is added to a solntion of phyllocyanin in boiling alcohol no combination takes place. A very different effect is observed when either of the two oxides is employed along with acetic acid. When cupric oxide is added to a solution of phyllocyanin in boiling acetic acid the solution acquires at once a deep greenish blue colour, and it no longer contains uncombined phyllocyanin, for its spectrum is different, and, on standing, it deposits lustrous crystals, which doubtless consist of a compound containing phyllocyanin, acetic acid, and copper. If zinc oxide be employed, a similar effect is observed : the liquid acquires an intense green colour like that of a chlorophyll solution, and now contains the corre. sponding acetate of phyllocyanin and zinc. The same phencmenon is seen when ferrous oxide, manganese oxide, or silver oxide is taken, liquids of various shades of green being obtained which contain phyllocyanin compounds; but no similar cornpounds are formed when potassium, sodium, barium, ca'cium, magnesium, or lead acetate is employed. Acetic acid is, however, not the only acid which yields the reaction. If palmitic, stearic, oleic, tartaric, citric, malic, or phosphoric acid te employed, it takes place just as with acetic acid, but in some cases time is required for its completion. Oxalic acid, however, seems to be without effect, and tartaric acid fails in some cases.

The behaviour of phyllocyanin towards zinc oxide in the presence of acids may serve to explain a peculiar phenomenon first observed by Prof. Church, and subsequently described by Tschirch. The former took chlorophyll that had become brown on standing, and, acting on it with zinc powder, obtained a body yielding green solutions, which he took to be regenerated chlorophyll. Tschirch acted on Hoppe-Seyler's chlorophyllan with zinc powder and observed the same phenomena, the conclusion at which he arrived being the same, viz. that chlorophyll 